\title{
Unified Ethics Amongst Diversified Cultures
}

\author{
Jerin Varghese Raji \\ Undergraduate student (First year MBBS) \\ Jawaharlal Nehru Medical College, Datta Meghe Institute of Medical Sciences (Deemed to be University), \\ Wardha (Maharashtra) \\ E-mail: jerinazero@gmail.com
}

Every human being, born in this world, after having completed a particular age, gets the wisdom of what is right and what is wrong, irrespective of their caste, color, creed, nationality, cultures, etc.......The only exception to the above said under normal circumstances are the special children(mentally disabled people in worldly terms). They are unaware of the distinction of what is right and wrong, thereby able to maintain their innocence until the very last moments of their lives. This idea of what is right and wrong is exactly what is referred to as ethics.

According to me, "Ethics is a unified and moralized set of understanding of the basic requisite of humanity which cannot be defined within boundaries based on laws, rules or regulations; thus an entity which couldn't be evaluated by comparison."

There are many people out there in this world from various backgrounds, practicing different customs and most importantly caring out their respective roles in this beautiful planet at various places.

These huge lot of variations in the world which we do live in, going simultaneously, is nothing less than a magical co-ordination, which is possible as a result of a universally common ethics applicable to the versatile people out there in this world.

Culture which is a very vast term incorporating different aspects of the life which we carry out, differs from person to person and from region to region. Each and every one of us in this world is born the same way but what a person ends up is as a result of the ways each one do frame their lives.

Just think what would be the scenario if you were born in a country which is neighboring to your present country. Everything would have been upside down from the foods you eat, to the dress you wear, to the way you look, the profession you do choose, etc

It all starts from where you were born and how you were brought up!!

All what you are now is the result of the cultures in which you were brought up. But irrespective of these varied cultures, ethics is one such attribute that remains unified and keeps you in pace with your other fellow beings with whom you do share this planet.

Each and every culture has its own identity, its own ideologies and as we all know its own teachings and practices. One can't say that a particular culture is the best. Everyone has a right to practice their own customs.

But in midst of all these differences we all are equally taught certain similar things. Majority do fade away from these childhood teachings but a mere minority do exist as such as they were before. These people are the life supporters of our world who do hold on to what they were taught in the childhood days because they realize the fact that these are the foundations of a happy living.

Let me give you, a very simple example...Each and every one of us were taught not to tell lies, not to steal, not to cheat irrespective of our cultures. But the thing is how often do we hold on to these 
ethical attributes matters the most (I accept the fact that many are also born into such environments were they are taught just the opposite). Being children, we to a good extend sticks firmly to these ethical things taught to us in different ways by different people through different cultures. But as we move ahead in the race of our life, somewhere or the other place we often fail to hold on to these ethics. We know the fact that we are going away from what is right but still we do find excuses to overwrite this inner soul feeling.

A student practicing proxies during lectures has no right to say that corruption should be abolished. If he or she does so, they are only deceiving themselves. The change should start from oneself.

People become extremists due to the lack of such basic underlying principle being not implemented in the day to day life and as a human being become more worse day by day. They earn a lot, to see from outer point of view; everything is perfect in their lives but only they do know the unsatisfactory status they go through.

How many of you who are reading this article didn't cheat even in a single exam? Just think and answer sincerely to your inner ethical being.

Suppose a child steals a pencil of his classmate in kindergarten. If this child is not taught the right, then he would dare to steal much bigger things when he grows up and would even end up being a criminal minded person at a latter part of his life.

Ethics doesn't mean that you always do what the law demands. According to law all patients are equal for a doctor and he or she has to deal with them in a chronological manner on the basic of first come, first consultation basis. But just thing suppose a patient is in a very severe condition and let there be 23 people waiting for consultation of the doctor who are with mild issues, do you think it would be wise to make the serious patient wait until the rest 23 ahead of him gets consulted, just because his number is 24 . According to law he should be consulted after the $23 \mathrm{rd}$ but according to ethics he should be consulted by the doctor first.

In particular countries one should keep left while driving whereas the scenario of the western countries asks its citizens to do keep right while driving. So, here if we do see then the culture of one country is that people should keep left while driving and of western country being to keep right. Cultures are different but there is one thing in common in both these situations i.e. a person should have the ethics to do follow the rules of the country in which he is driving.

In this ever changing modernized world of technologies where life does get a pause to selfintrospect, it's the need of the hour to start finding out some time for oneself and bring out the best in oneself irrespective of the varied culture in which we all were brought up in. This is possible only by holding on to the great ethical teachings which we received during the course of our life. The particular need as such cannot be pointed out for the following of ethics in our personal day to day life as each and every little aspect of our life is governed by these ethical attributes and these are far beyond the scope of just typing down.

Acknowledgements - Nil

Source of Funding - Nil

Conflict of Interest - Nil 